\title{
Hepatoprotective Effect of Corm of Ensete ventricosum (Welw.) Cheesman Extract against Isoniazid and Rifampicin Induced Hepatotoxicity in Swiss Albino Mice
}

\author{
Abebe Dukessa Dubiwak (D), ${ }^{1}$ Tesaka Wondimnew Damtew, ${ }^{1}$ Mengistu Welde Senbetu, ${ }^{1}$ \\ Delenasaw Yewhalaw, ${ }^{2}$ Tsegaye Girma Asere, ${ }^{3}$ Gebi Nemo, ${ }^{4}$ and Minale Fekadie Baye ${ }^{1}{ }^{1}$ \\ ${ }^{1}$ Division of Medical Biochemistry, Department of Biomedical Sciences, Institute of Health Sciences, Jimma University, \\ Jimma, Ethiopia \\ ${ }^{2}$ Department of Medical Laboratory Sciences and Pathology, College of Health Sciences, Institute of Health Sciences, \\ Jimma University, Jimma, Ethiopia \\ ${ }^{3}$ Department of Chemistry, College of Natural Sciences, Jimma University, Jimma, Ethiopia \\ ${ }^{4}$ Department of Pathology, Institute of Health Sciences, Jimma University, Jimma, Ethiopia
}

Correspondence should be addressed to Abebe Dukessa Dubiwak; dubiwak.2020@gmail.com

Received 19 May 2021; Revised 11 July 2021; Accepted 6 August 2021; Published 13 August 2021

Academic Editor: Pamela Jha

Copyright (c) 2021 Abebe Dukessa Dubiwak et al. This is an open access article distributed under the Creative Commons Attribution License, which permits unrestricted use, distribution, and reproduction in any medium, provided the original work is properly cited.

\begin{abstract}
Drug-induced liver injury (DILI) is one of the cumbersome health-related problems which render approximately $50 \%$ of liver failure and patients to receiving liver transplantation every year. Antituberculosis drugs such as isoniazid and rifampicin are potentially rendering hepatotoxicity. Ensete ventricosum (Welw.) Cheesman is an herbaceous perennial plant that contributes to the indigenous ethnomedicinal values for the society. This study aimed to investigate the hepatoprotective effect of corm of Ensete ventricosum (Welw.) Cheesman extracts against isoniazid and rifampicin induced hepatotoxicity in Swiss albino mice. The study was conducted on 30 Swiss albino mice randomly allocated into five groups. Group I, group II, group III, group IV, and group V were the groups in which mice were given distilled water, only isoniazid and rifampicin, isoniazid and rifampicin along with $200 \mathrm{mg} / \mathrm{kg}$ corm of Ensete ventricosum (Welw.) Cheesman extract, isoniazid and rifampicin along with $400 \mathrm{mg} / \mathrm{kg}$ corm of Ensete ventricosum (Welw.) Cheesman extract, and isoniazid and rifampicin along with silymarin per oral per day, respectively. On the 30th day of the experiment, mice were sacrificed after anesthetized, and blood was drawn for the liver function test, and the liver was also taken from each experimental mouse for histopathological evaluation. Data were entered into EpiData version 3.1 subsequently exported to SPSS version 25 for analysis by using one-way ANOVA. Plasma alanine aminotransferase (ALT) levels, aspartate aminotransferase (AST), alkaline phosphatase (ALP), and total bilirubin (TBIL) of group II mice were significantly $(p<0.05)$ elevated as compared to group I. The group of mice treated with a corm of Ensete ventricosum (Welw.) Cheesman at a dose of $400 \mathrm{mg} / \mathrm{kg}$ (group IV) and silymarin $100 \mathrm{mg} / \mathrm{kg}$ (group V) showed a significant $(p<0.05$ ) decrease in ALT, AST, ALP, and TBIL as compared to the group II. The liver section of group II showed a change in liver architecture; however, these deformities were not noticed in group IV mice. The result showed corm of Ensete ventricosum (Welw.) Cheesman extract has a very promising hepatoprotective potential against isoniazid and rifampicin induced liver injury.
\end{abstract}

\section{Introduction}

Hepatotoxicity is one of the cumbersome complications that can be mainly caused by overdoses of certain medicinal drugs, industrial chemicals, even dietary supplements, and excess consumption of alcohol $[1,2]$.
Being the liver is the principal organ in the drug metabolism, exposes the organ to toxic injury and makes it the most frequently targeted organ in drug toxicity $[3,4]$. The most frequent hepatotoxic drug reactions evoke moderate-to-severe injury to hepatocytes $[5,6]$. Biochemical indicators of hepatocellular injury are a rise of liver 
biomarkers such as aspartate transaminase (AST), alanine transaminase (ALT), alkaline phosphatase (ALP), and total bilirubin (TBIL) $[7,8]$.

The usual drugs associated with hepatotoxicity are antituberculosis (anti-TB) drugs, which are utilized to treat tuberculosis disease [9]. Isoniazid (INH) and rifampicin (RIF) are anti-TB drugs that have been treating TB-infected individuals. They are metabolized in the liver and the principal agents responsible for anti-TB drug-induced hepatotoxicity $[9,10]$.

INH and its metabolites (such as hydrazine) are associated with serious hepatotoxicity and potentially fatal liver injury $[11,12]$. INH also induced hepatotoxicity via generating ROS that leads to oxidative stress. Hydrazine can generate oxygen radicals or superoxide and the isoniazid treatment increment of superoxide [11].

Patients on isoniazid coadministration with rifampicin therapy have increased hepatotoxicity [13]. In a metaanalysis, it was revealed that rifampicin increased the prevalence of drug-induced liver injury in a multidrug regimen from $1.6 \%$ to $2.55 \%$ in adults [14]. Hepatotoxicity attributed to anti-TB drugs has been reported $5-34.9 \%$ in people treated with anti-TB drugs $[15,16]$.

Antituberculosis drugs induced hepatotoxicity (anti-TB $\mathrm{DIH}$ ) is a major problem in HIV coinfection TB immunocompromised in Ethiopia [17]. A study performed in Ayder Referral Hospital of Tigray regional state showed that TB/HIV coinfected patients treated with antituberculosis developed grade one hepatotoxicity and severe hepatotoxicity ( $\geq$ grade 2 ) $45 \%$ and $15 \%$, respectively [18]. In Jimma Medical Center in 2013, the incidence of anti-TB drug-induced hepatotoxicity was $11.5 \%$ [19].

Ensete ventricosum (Welw.) Cheesman belongs to the monocotyledonous and monocarpic family Musaceae and is an herbaceous perennial plant [20]. It is the source of more than 10 minerals which include calcium $(\mathrm{Ca})$, sodium $(\mathrm{Na})$, potassium $(\mathrm{K})$, magnesium $(\mathrm{Mg})$, iron $(\mathrm{Fe})$, manganese $(\mathrm{Mn})$, copper $(\mathrm{Cu})$, and zinc $(\mathrm{Zn})[20,21]$.

Besides, to use it as a staple and costaple food for millions of Ethiopians contributes to indigenous ethnomedicinal values of the society. Ensete ventricosum (Welw.) Cheesman is used in traditional for treating liver diseases, expel of the placenta, treatment of cough, dysentery, healing of the bone fracture, diabetes, kidney stone, and dysuria, and antimicrobial activity against viral, bacterial, fungal, and nematode diseases of humans [22-24]. Several minerals and phytochemicals in the extract corm of the Ensete genus have the capability of the cell-protective effect via scavenging free radicals and boosting the antioxidant defense system (AODS) [21, 25-28], but no study is performed on its hepatoprotective effect yet. Therefore, this study had revealed a hepatoprotective effect of the corm of Ensete ventricosum (Welw.) Cheesman against hepatotoxicity induced by anti-TB drugs.

\section{Materials and Methods}

2.1. Plant Collection and Authentication. Ensete ventricosum (Welw.) Cheesman was obtained from Oromia region,
Southwest Shoa, Wanci woreda, and then subsequently authenticated by plant taxonomist at Addis Ababa University National Herbarium, and AD-001/2020 voucher number was given, and the plant leaf was deposited at the herbarium for further reference.

2.2. Plant Extraction. The corm of Ensete ventricosum (Welw.) Cheesman is the underground part of Ensete ventricosum (Welw.) Cheesman. It was dug out, and the corm was uprooted from the soil, the root was removed from it, and chopped into small pieces. It was air-dried under a shaded area at room temperature. The gross weight of the chopped corm of Ensete was $400 \mathrm{~g}$ which was then ground into coarse powder and macerated by using $80 \%$ methanol.

The extract was filtered, and then, methanol solution was evaporated by a rotary evaporator to have a solid consistency and dried by a freeze dryer (lyophilizer). Finally, residue extract was packed in air-tight glass bottles with proper labels and kept in a refrigerator at $4^{\circ} \mathrm{C}$ until used for the experiment.

\subsection{Preliminary Phytochemical Screening of the Extract.} Testing for alkaloids, terpenoid, flavonoid, phenol, steroid, quinone, saponin, tannin, and glycoside of hydromethanolic extract of corm of Ensete ventricosum (Welw.) Cheesman was performed by following procedures obtained from previous studies [29].

2.4. Experimental Animals. A total of 30 either sexes, $8-10$ weeks old, and weighing 30-41 g Swiss albino mice were obtained from Jimma University Tropical and Infectious Disease Research Center (JUTIDRC), Sokoru, Jimma, Ethiopia. The experimental animals were allowed to acclimatized laboratory conditions at Jimma University College of Agriculture and Veterinary Medicine (JUCAVM), postgraduate Veterinary Medicine Laboratory, for two weeks before the experiment was commenced. Standard food pellets (ad libitum) and tap water were supplied for animals at all times. The animals were maintained on a $12 \mathrm{~h}$ light/ dark cycle in an ambient temperature $\left(20-25^{\circ} \mathrm{C}\right)$ and humidity environment. At the end of two weeks, experimental animals were randomly grouped into 5 groups each group consisting of 6 mice.

2.5. Drug Dose for Inducing Hepatotoxicity. The INH and RIF doses for inducing liver damage were $75 \mathrm{mg} / \mathrm{kg}$ and $150 \mathrm{mg} / \mathrm{kg}$ administered per oral (PO) by gavage, respectively [30].

2.6. Grouping of Experimental Animals and Treatment Protocol. The doses of INH and RIF to induce hepatotoxicity were used from previous studies [30], and the initial dose of the corm of Ensete ventricosum (Welw.) Cheesman extract was $10 \%$ of $2000 \mathrm{mg} / \mathrm{kg}$ because an extract of Ensete had no toxicity effect up to $2000 \mathrm{mg} / \mathrm{kg}$ [28]; then, the second dose was two folds of the initial dose which was $20 \%$ of $2000 \mathrm{mg} / \mathrm{kg}(400 \mathrm{mg} / \mathrm{kg})$ according to OECD guidelines. 
(1) Group I (normal control group): representing mice received $1 \mathrm{ml} / \mathrm{kg}$ of distilled water PO daily for thirty days

(2) Group II (negative control): representing mice received INH $75 \mathrm{mg} / \mathrm{kg}$ plus RIF $150 \mathrm{mg} / \mathrm{kg}$ PO daily for thirty days

(3) Group III (experimental): representing mice received corm of Ensete ventricosum (Welw.) Cheesman extract $200 \mathrm{mg} / \mathrm{kg}$ and INH $75 \mathrm{mg} / \mathrm{kg}$ plus RIF $150 \mathrm{mg} / \mathrm{kg}$ PO daily for thirty days

(4) Group IV (experimental): representing mice received corm of Ensete ventricosum (Welw.) Cheesman extract $400 \mathrm{mg} / \mathrm{kg}$ and INH $75 \mathrm{mg} / \mathrm{kg}$ plus RIF $150 \mathrm{mg} / \mathrm{kg}$ PO daily for thirty days

(5) Group V (silymarin control): representing mice received silymarin $100 \mathrm{mg} / \mathrm{kg}$ and $\mathrm{INH} 75 \mathrm{mg} / \mathrm{kg}$ plus RIF $150 \mathrm{mg} / \mathrm{kg}$ PO daily for thirty days [31]

2.7. Bodyweight and Liver Index (Liver/Bodyweight \%). The bodyweight of the mice was measured weekly to see bodyweight change in all groups of experimental animals. The liver index was calculated as the liver weight of each mouse divided by their respective bodyweight multiplied by $100(\mathrm{~g} / \mathrm{g})$.

2.8. Blood Collection and Serum Preparation from Mice. On the $30^{\text {th }}$ day, the mice were fasted overnight and anesthetized by $100 \mathrm{mg} / \mathrm{kg}$ ketamine $/ 12.5 \mathrm{mg} / \mathrm{kg}$ xylazine injection. The mice were euthanized by cervical dislocation after cardiac puncture for blood collection. About 2-2.5 ml of blood collected from each mouse was placed in a serum separating test tube and left for 30 minutes at room temperature to clot. The serum was separated using a micropipette $(1000 \mu \mathrm{l})$ after centrifugation with the speed of $3000 \mathrm{rpm}$ at room temperature for 10 minutes, and isolated serum was stored at $-20^{\circ} \mathrm{C}$ until serum was analyzed for the liver biomarker.

2.9. Biochemicals Analysis. From serum, the liver damage biomarkers are the ALT, AST, ALP, and TBIL analyzer according to the standard principles and procedures of the kit manufacturer manual.

2.10. Histopathological Study. The liver tissue was taken from each mouse carefully after the mice were sacrificed via dissection from the neck to the pubis and opened the peritoneum by using a sterile surgical blade. The liver tissue was preserved by $10 \%$ of buffered neutral formalin in saline. After the tissues were processed and embedded in paraffin wax, $5 \mathrm{~mm}$ thick sections were taken and stained with hematoxylin and eosin for histopathological examination.

2.11. Statistical Tests. The protective effect of the intervention among experimental groups of animals was done by using SPSS statistical software package version 25 . To evaluate mean differences of various parameters between the groups use one-way ANOVA, followed by post hoc. Tukey and $p$ value less than 0.05 were considered statistically significant. The microscopic evaluation was a qualitative analysis carried out by a senior pathologist through preparing microscopic slides for each group and presented in the form of photomicrography.

2.12. Ethical Approval. This study was performed after the ethical clearance letter obtained from the Research and Ethical Review Committee of the Institute of Health, Jimma University, with a protocol number of Ref.No. IHRPGD/ $714 / 2020$. The uses of animals and all activities in this experimental study were carried out according to the regulation of animal care and use of JUCAVM.

\section{Results}

3.1. Result of the Phytochemical Screening Test. The result of phytochemical screening of the hydromethanolic extract of the corm of Ensete ventricosum (Welw.) Cheesman showed the presence of bioactive constituents such as alkaloid, flavonoid, steroid, quinone, saponin tannin, and glycosides (Table 1).

3.2. Bodyweight of the Mice. The initial mean weight of the mice was $37.00 \pm 2.60 \mathrm{~g}$ ( 30 to $41 \mathrm{~g}$ ). Between all groups, the mean bodyweight of the mice at $1^{\text {st }}, 2^{\text {nd }}, 3^{\text {rd }}$ and $4^{\text {th }}$ week were insignificant differences $(p>0.05)$, despite group II mean bodyweight were numerical decrement from the first week to the fourth week (Figure 1) when compared with the mean bodyweight of group I.

3.3. Effect of Corm of Ensete ventricosum (Welw.) Cheesman Extract on Liver Enzyme Parameters and Serum Total Bilirubin in Isoniazid and Rifampicin Challenged Mice. The effect of corm of Ensete ventricosum (Welw.) Cheesman extract on liver enzyme parameters and serum total bilirubin (TBIL) in isoniazid and rifampicin challenged mice is given in Table 2.

3.4. Effect of Corm of Ensete ventricosum (Welw.) Cheesman Extract on Liver Index (Liver/Bodyweight \%). The liver index in different experimental groups of mice is given in Table 3.

3.5. Liver Histopathological Findings. Microscopic examination of the liver sections of mice showed a visible difference in the liver architecture between the controls and the treatment groups. As we can observe from the microscopic slide, in the normal control group of mice, the liver section showed normal hepatic parenchyma composed of the plate of hepatocytes, central vein, and portal tracts with portal veins, hepatic vessels, and bile ducts (Figure 2(a)). In contrast, the liver section slide of the isoniazid and rifampicin only treated group showed hepatic parenchymal composed of hepatocyte with hypertrophy, mild-moderate vacuolar degeneration, mild necrosis, fatty change, and mild mixed 
TABLE 1: The result of preliminary phytochemical screening of hydromethanolic extract of the corm of Ensete ventricosum (Welw.) Cheesman.

\begin{tabular}{lccc}
\hline Phytochemical constituent & Result & Phytochemical constituent & Result \\
\hline Alkaloid & + & Quinone & + \\
Terpenoid & - & Saponins & + \\
Flavonoid & + & Tannin & + \\
Phenol & - & Glycosides & + \\
Steroid & + & & \\
\hline
\end{tabular}

"+" stands for the presence of phytochemicals; “-” stands for the absence of phytochemicals.

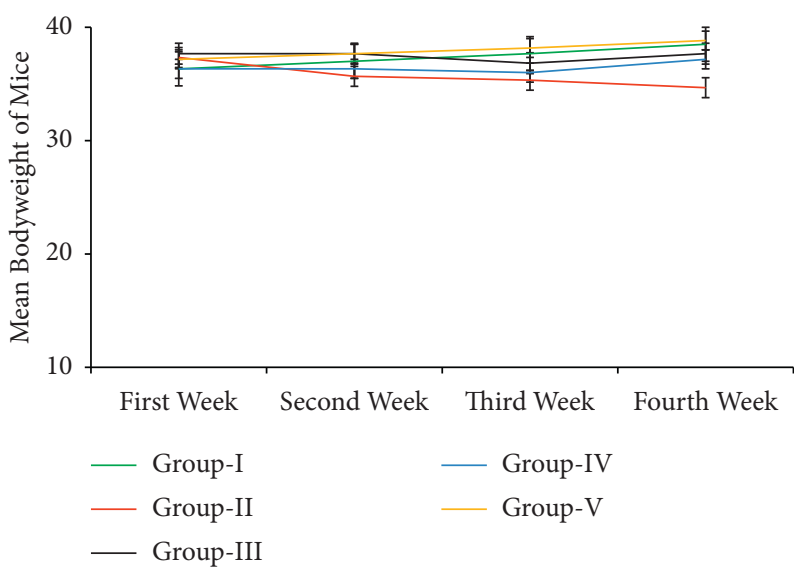

FIGURE 1: The mean bodyweight of the Swiss albino mice from the first week to the fourth week (the results are expressed as mean \pm SE).

TABLE 2: Effect of corm of Ensete ventricosum (Welw.) Cheesman extract on liver enzyme parameters and serum total bilirubin (TBIL) in isoniazid and rifampicin challenged mice.

\begin{tabular}{|c|c|c|c|c|}
\hline Groups & ALT (IU/L) & AST (IU/L) & $\operatorname{ALP}(\mathrm{IU} / \mathrm{L})$ & TBIL \\
\hline Group I (normal control) & $34.66 \pm 3.42^{\mathrm{a}}$ & $53.67 \pm 4.40^{\mathrm{a}}$ & $98.33 \pm 2.49^{\mathrm{a}}$ & $0.12 \pm 0.01^{\mathrm{a}}$ \\
\hline Group II (INH and RIF) & $123.67 \pm 3.25^{\mathrm{d}}$ & $152.83 \pm 3.84^{\mathrm{d}}$ & $171.00 \pm 4.69^{c}$ & $0.28 \pm 0.02^{\mathrm{b}}$ \\
\hline Group III (extract $200 \mathrm{mg} / \mathrm{kg}$ ) & $90.00 \pm 4.89^{c}$ & $87.50 \pm 4.96^{\mathrm{c}}$ & $120.83 \pm 3.75^{\mathrm{b}}$ & $0.21 \pm 0.03^{\mathrm{ab}}$ \\
\hline Group IV (extract $400 \mathrm{mg} / \mathrm{kg}$ ) & $53.17 \pm 4.95^{\mathrm{b}}$ & $75.33 \pm 3.21^{\mathrm{bc}}$ & $108.00 \pm 4.09^{\mathrm{ab}}$ & $0.19 \pm 0.03^{\mathrm{a}}$ \\
\hline Group V (silymarin control) & $40.16 \pm 3.09^{\mathrm{ab}}$ & $62.17 \pm 1.62^{\mathrm{ab}}$ & $106.33 \pm 2.40^{\mathrm{ab}}$ & $0.13 \pm 0.01^{\mathrm{a}}$ \\
\hline
\end{tabular}

The results are expressed as mean \pm SE. Values with different superscripts within the same column are statistically significant $(p<0.05)$.

TABLE 3: Liver index in different experimental groups of mice.

\begin{tabular}{lc}
\hline Groups & Liver index (L/BW \%) \\
\hline Group I (normal control) & $5.85 \pm 0.30^{\mathrm{a}}$ \\
Group II (INH and RIF) & $7.54 \pm 0.23^{\mathrm{c}}$ \\
Group III (extract $200 \mathrm{mg} / \mathrm{kg})$ & $6.89 \pm 0.20^{\mathrm{bc}}$ \\
Group IV (extract $400 \mathrm{mg} / \mathrm{kg})$ & $6.14 \pm 0.17^{\mathrm{ab}}$ \\
Group V (silymarin control) & $6.00 \pm 0.25^{\mathrm{ab}}$ \\
\hline
\end{tabular}

The results are expressed as mean \pm SE. Values with different superscripts within the same column are statistically significant $(P<0.05)$.

inflammation cells infiltration throughout parenchymal including the portal area (Figure 2(b)). However, the group of mice treated orally with the corm of Ensete ventricosum (Welw.) Cheesman extract significantly regenerated the liver architecture in isoniazid and rifampicin treated mice, and a dose-dependent difference in regenerative capacity was observed between group III $(200 \mathrm{mg} / \mathrm{kg})$ and group IV $(400 \mathrm{mg} / \mathrm{kg})$. The silymarin treatment also significantly regenerated the liver architecture in isoniazid and rifampicin treated mice (silymarin control) compared to only the isoniazid and rifampicin treated group, eventhough there is minor infiltration.

\section{Discussion and Conclusion}

A serious adverse drug reaction of the antituberculosis treatment is hepatotoxicity [9]. In the present study, after daily administration of the INH $75 \mathrm{mg} / \mathrm{kg}$ and RIF $150 \mathrm{mg} /$ $\mathrm{kg}$ ) for 30 days, the hepatotoxicity was confirmed by significant elevation of the serum level of liver enzymes such as ALT $(p<0.01)$, ALP $(p<0.01)$, and AST $(p<0.01)$ levels in the mice orally administered of INH and RIF (group II) as compared to the mice orally administered with distilled water (Table 2). Meanwhile, an obvious death of hepatocytes, accompanied by mild necrosis, inflammatory infiltration, mild-moderate vacuolar change with vacuolar degeneration, and fatty degeneration throughout all hepatic parenchymal was also observed in the liver section of mice treated with only INH and RIF (Figure 2(b)). This finding is in harmony 


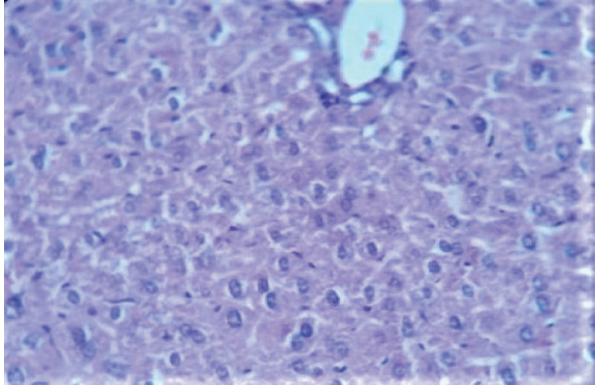

(a)

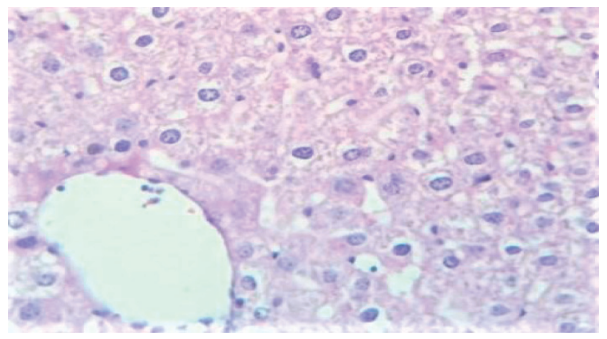

(c)

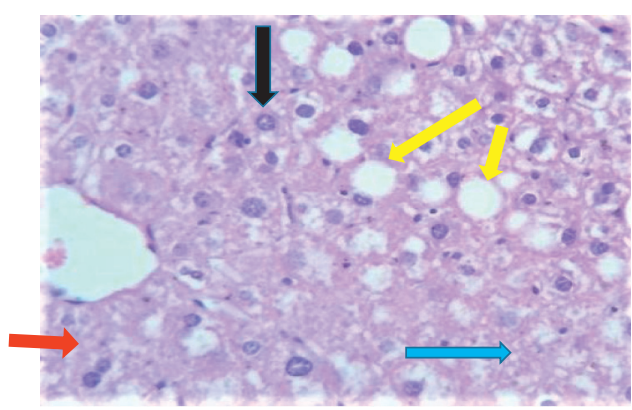

(b)

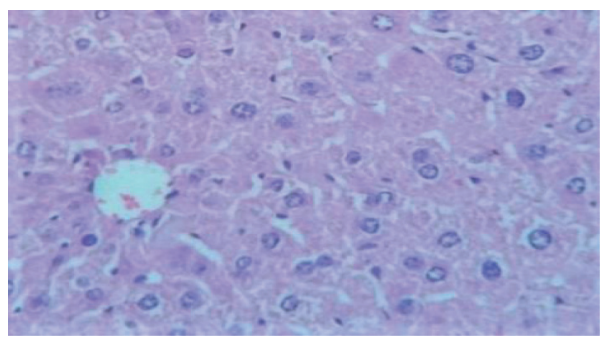

(d)

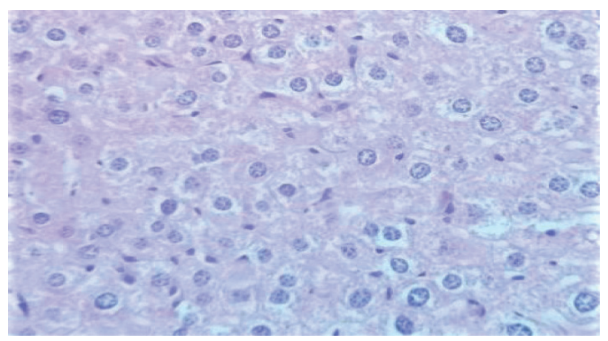

(e)

FIGURE 2: Photomicrograph of the liver of experimental animals (stained with hematoxylin and eosin). Group I (a); group II (b); group III (c), group IV (d), and group V (e). Red arrow, hypertrophy; black arrow, vacuolar change; yellow arrow, fatty change, and blue arrow inflammatory infiltration.

with the previous studies done by Shabbir et al. [16], Chen et al. [30], and Siddique et al. [32].

The plausible explanation of the INH and RIF that causes hepatocellular damage and attribute the elevation of the liver enzymes level in the serum is during reactive metabolites of those drugs covalently bound macromolecules of the cell (hepatocyte), resulting in depriving cellular integrity and liver enzymes released from the cell to the blood [33, 34]. Additionally, these anti-TB drugs could cause cellular damage through the induction of oxidative stress as a consequence of the depletion of glutathione (GSH)/glutathione peroxidase (GPx), superoxide dismutase (SOD), and catalase (CAT) levels within hepatocytes via activation of CYP2E1 [33-35].

Treatment with hydromethanolic extract of corm of Ensete ventricosum (Welw.) Cheesman restored the serum level of liver enzymes near to normal in the INH and RIF challenged mice. The corm of Ensete ventricosum (Welw.) Cheesman extract treatment at a dose of $200 \mathrm{mg} / \mathrm{kg}$ (group III) showed a significant reduction $(p<0.05)$ of ALT, AST, and ALP levels in the INH and RIF treated mice as compared to only the INH and RIF treated group (group II). Moreover, treatment at a higher dose $(400 \mathrm{mg} / \mathrm{kg})$ lowered the level of liver enzymes near to normal $(p<0.01)$ in the INH and RIF treated mice as compared to the INH and RIF only treated group. Treatment with silymarin (group V) also showed a significant reduction $(p<0.01)$ in the level of liver enzymes in INH and RIF treated mice compared to the INH and RIF only treated group (Table 2).

Other studies were performed on the hepatoprotective effect of the Musaceae family, like fruit pulp extract of Musa paradisiaca and stems of Musa sapientum Linn. against carbon tetrachloride-induced in rats similar to our finding $[36,37]$. This may be due to synergistic activities of phytochemicals in the hydromethanolic corm of Ensete ventricosum (Welw.) Cheesman extract which have the capability to decreasing CYP2E1 enzymatic activity of alkaloid [38], antioxidative, and free radical scavenging properties of tannin, important in protecting cellular oxidative damage including lipid peroxidation [39, 40], antioxidant action by enzyme zinc-dependent superoxide dismutase [21,32], hepatoprotective activity via modulation of its antioxidant of saponin [41, 42], and flavonoid [43].

INH and RIF only treated group of mice (group II) had statistically significant $(p<0.01)$ increment of total bilirubin as compared to a normal control group of mice (group I) 
(Table 2). This finding was in line with the study performed by Naji et al. [34] and Chandra and Shanmugapandivan [35]. This might be due to the combination of INH and RIF resulted in a higher rate of inhibition hepatic clearance of bile, an increase in lipid peroxidation in the hepatocyte, and cytochrome P450 involved in the synergistic effect of RIF and INH $[34,35,44]$.

Treatment with the corm of Ensete ventricosum (Welw.) Cheesman extract lowered serum total bilirubin in INH and RIF treated mice. The mice treated with INH and RIF plus corm of Ensete ventricosum (Welw.) Cheesman extract at a dose of $400 \mathrm{mg} / \mathrm{kg}$ significantly reduced $(p<0.05)$ as compared to INH and RIF only treated mice (Table 2 ). This result has consistency with studies performed on the hepatoprotective effect against INH and RIF induced hepatotoxicity of Cassia fistula leaves by Ilyas et al. [45] and Eclipta alba by Chandra and Shanmugapandivan [35]. This might be due to the presence of secondary metabolites that render to restore injured hepatocytes such as flavonoids, steroids, tannins, saponins, and alkaloids. The corm of the Ensete ventricosum (Welw.) Cheesman also consists of those secondary metabolites. Moreover, a significant decrease $(p<0.01)$ total bilirubin level was observed in the silymarin $(100 \mathrm{mg} / \mathrm{kg})$ treated mice as compared to only the INH and RIF treated mice.

Furthermore, the present study pointed out a notable $(p<0.01)$ increased in the liver index in coadministration of INH with RF mice (group I) (Table 3). This finding is consistent with earlier study done by Tilaye et al. [46]. Also, this result revealed that corm of Ensete ventricosum (Welw.) Cheesman extract at $400 \mathrm{mg} / \mathrm{kg}$ (group IV) causes a significant $(p<0.01)$ decrement of the liver index in INH and RIF treated groups as compared to only INH and RIF treated group (Table 3 ). Silymarin treated group also has a comparable result. This is probably due to the healing of the liver to perform all its physiological functions including burning the fat it had accumulated inside its cells.

Microscopic examination of the liver sections of mice showed a visible difference in the liver architecture between the controls and the treatment groups (Figures 2(a)-2(e)). The liver section slide of the INH and RIF only treated group showed hepatic parenchymal composed of hepatocyte with hypertrophy of hepatocytes in the central area of the lobule, moderate vacuolar change, and vacuolar degeneration around the portal area, with mild inflammatory cell infiltration throughout parenchymal includes portal area and fatty change (Figure 2(b)).

The present finding supported by the previous studies Liu et al. [8] reported on bile, lipid, and purine metabolism involved in the hepatotoxicity of first-line antituberculosis drugs, Huang et al. [47] reported rifampicin induced hepatic lipid accumulation, and Dong et al. Wali et al. [48], Evan et al. [33], and Bais and Saiju [49] reported isoniazid plus rifampicin induced liver injury in mice. It is reasonable to assume that rifampicin-activated PXR is involved in the upregulation of genes for fatty acid synthesis. In addition to hepatic de novo lipogenesis, the increased uptake of free fatty acids from circulation to the liver plays an important role in the development of hepatic lipid accumulation [47].
However, the group of mice treated orally with the corm of Ensete ventricosum (Welw.) Cheesman extracts significantly regenerated the liver architecture in INH and RIF treated mice, and a dose-dependent difference in regenerative capacity was observed between group III and group IV (Figures 2(c) and 2(d)). This perhaps is due to the antihyperlipidemic effect of glycosides, antioxidant effect of saponins, and anti-inflammatory effect of flavonoids [50] in the corm of Ensete ventricosum (Welw.) Cheesman.

The silymarin treatment also significantly regenerated the liver architecture in INH and RIF treated mice (silymarin control) (Figure 2(e)) compared to only the INH and RIF treated group (Figure 2(b)), eventhough there is minor infiltration. Maybe due to it inhibits several isoforms of CYT P450 enzymes, potentiates the antioxidant capacity of the liver, acts as a scavenger of oxygen free radicals, inhibits the synthesis of proinflammatory cytokines, and enhances apoptosis [46].

4.1. Conclusion. The protective effect of the corm of Ensete ventricosum (Welw.) Cheesman extracts at dose $400 \mathrm{mg} / \mathrm{kg}$ is comparable with the hepatoprotective effect of the silymarin which is standard hepatoprotective. Therefore, the finding of this study, along with the above facts, strongly suggests that hydromethanolic extract of the corm of Ensete ventricosum (Welw.) Cheesman has hepatoprotective properties, which are mediated by perhaps due to their phytochemicals property.

\section{Data Availability}

The data used to support the findings of this study are available from the corresponding author upon request.

\section{Conflicts of Interest}

The authors declare that they have no conflicts of interest.

\section{Acknowledgments}

The authors thank JUCAVM and JUTIDRC.

\section{References}

[1] S. Sivakrishnan, "Liver disease overview," World Journal of Pharmacy and Pharmaceutical Sciences, vol. 8, no. 1, pp. 1385-1395, 2019.

[2] X. Yang, L. K. Schnackenberg, Q. Shi, and W. F. Salminen, "Hepatic toxicity biomarkers," Biomarkers in Toxicology, vol. 1, pp. 241-259, 2014.

[3] L. Sha, T. Hor-yue, W. Ning et al., "The role of oxidative stress and antioxidants in liver diseases," International Journal of Molecular Sciences, vol. 16, no. 8, pp. 26087-26124, 2015.

[4] A. A. Omar, K. M. Mohammad, and V. Raman, "Drug metabolism in the liver," Clinics in Liver Disease, vol. 21, no. 1, pp. 1-20, 2017.

[5] M. L. William, "Drug-induced hepatotoxicity," New England Journal of Medicine, vol. 349, no. 5, pp. 474-485, 2003.

[6] J. Cheng, K. W. Krausz, F. Li, X. Ma, and F. J. Gonzalez, "CYP2E1-dependent elevation of serum cholesterol, 
triglycerides, and hepatic bile acids by isoniazid," Toxicology and Applied Pharmacology, vol. 266, no. 2, pp. 245-253, 2013.

[7] R. Pal, S. V. Rana, K. Vaiphei, and K. Singh, "Isoniazid-rifampicin induced lipid changes in rats," Clinica Chimica Acta, vol. 389 , no. $1-2$, pp. 55-60, 2008.

[8] L. Liu, X. Li, C. Huang et al., "Bile acids, lipid and purine metabolism involved in hepatotoxicity of first-line anti-tuberculosis drugs," Expert Opinion on Drug Metabolism and Toxicology, vol. 16, no. 6, pp. 527-537, 2020.

[9] S. V. Rana, S. K. Sharma, R. P. Ola et al., "N-acetyltransferase 2, cytochrome P4502E1 and glutathione S-transferase genotypes in antitubercular treatment-induced hepatotoxicity in North Indians," Journal of Clinical Pharmacy and Therapeutics, vol. 39, no. 1, pp. 91-96, 2014.

[10] World Health Organization, "Treatment of tuberculosis," WHOI, vol. 95, no. 34-36, pp. 1991-1992, 2010.

[11] I. G. Metushi, P. Cai, X. Zhu, T. Nakagawa, and J. P. Uetrecht, "A fresh look at the mechanism of isoniazid-induced hepatotoxicity," Clinical Pharmacology and Therapeutics, vol. 89, no. 6, pp. 911-914, 2009.

[12] W. Pengcheng, P. Komal, Z. Xiao-bo, and M. Xiaochao, "Isoniazid metabolism and hepatotoxicity," Acta Pharmaceutica Sinica B, vol. 14, no. 7, pp. 1-9, 2016.

[13] A. Shabnam, A. K. Mohammad Akhtar Siddiqui Asim, J. Aftab Ahmad Azhar et al., "Experimental models and hepatotoxic agents used to study hepatoprotective effect of traditional drugs," International Journal of Advances in Pharmacy Medicine and Bioallied Sciences, vol. 2, no. 3, pp. 67-74, 2014.

[14] A. Saha, M. Shanthi F.X., B. Winston et al., "Prevalence of hepatotoxicity from antituberculosis therapy," Journal of Primary Care and Community Health, vol. 7, no. 3, pp. 171174, 2016.

[15] V. R. Satya, P. Ravinder, V. Kim, and S. Kartar, "Effect of different oral doses of isoniazid-rifampicin in rats," Molecular and Cellular Biochemistry, vol. 289, no. 137, pp. 39-47, 2006.

[16] M. Shabbir, T. Afsar, S. Razak, A. Almajwal, and M. R. Khan, "Phytochemical analysis and evaluation of hepatoprotective effect of maytenus royleanus leaves extract against anti-tuberculosis drug induced liver injury in mice," Lipids in Health and Disease, vol. 19, no. 1, pp. 46-15, 2020.

[17] G. Yimer, G. Aderaye, W. Amogne et al., "Anti-tuberculosis therapy-induced hepatotoxicity among Ethiopian HIV-positive and negative patients," PLoS One, vol. 3, no. 3, p. e1809, 2008.

[18] A. W. Minyahil, G. Z. Addishiwot, and L. L. Jimma, "Assessment of drug induced hepatoxicity in pateints treated for TB/HIV co-infection in Ayder referal hospital ART clinic, Mekelle, Ethiopia," European Journal of Biomedical and Pharmaceutical Sciences, vol. 1, no. 2, pp. 22-34, 2014.

[19] H. A. Alima, B. Tefera, Y. Alemeshet, and Y. A. Wubeante, "Anti-tuberculosis drug induced hepatotoxicity among TB/ HIV co-infected patients at Jimma University hospital , Ethiopia," PLoS One, vol. 8, no. 5, pp. 1-8, 2013.

[20] N. Ajebu, T. Adugna, and O. E. Lars, "Yield and mineral content of ten enset (Ensete ventricosum) varieties," Tropical Animal Health and Production, vol. 40, pp. 299-309, 2008.

[21] W. N. Gizachew, F. Tileye, D. Sebsebe, T. Kassahun, and Z. W. Ashagrie, "Comparison of proximate, mineral and phytochemical composition of enset (Ensete ventricosum (Welw.) Cheesman) landraces used for a different purpose," African Journal of Agricultural Research, vol. 14, no. 30, pp. 1326-1334, 2019.

[22] B. Genene, P. Ramachandra, Ethnobotanical study of medicinal plants used to treat human ailments by Guji Oromo tribes in Abaya district,Borana, Oromia, Ethiopia," Universal Journal of Plant Science, vol. 3, no. 1, pp. 1-8, 2015.

[23] A. Kedir, "Traditional medicinal use of ensete ventricosum (welw.) cheesman in gedebano gutazer welene District, Gurage zone, SNNP region,” Technology, vol. 1, no. 1, pp. 1-17, 2016.

[24] M. Melesse, N. Sileshi, and B. Tamirat, "An ethnobotanical study of medicinal plants of the Kembatta ethnic group in Enset-based agricultural landscape of Kembatta Tembaro ( KT ) Zone, Southern, Ethiopia," Asian Journal of Plant Science \& Research, vol. 5, no. 7, pp. 42-61, 2019.

[25] N. K. Sethiya, K. Brahmbhat, B. Chauhan, and S. H. Mishra, "Pharmacognostic and phytochemical investigation of Ensete superbum (Roxb.) Cheesman pseudostem," Indian Journal of Natural Products and Resources, vol. 7, no. 1, pp. 51-58, 2016.

[26] P. Kumar, S. K. Badgujar, and N. VN, "Preliminary screening of different phytochemicals from Ensete superbum ( roxb .) Cheesman: a highly medicinal plant of Indian origin," International Journal of Pharmaceutical and Phytopharmacological Research, vol. 3, no. 1, pp. 57-60, 2013.

[27] R. N. Kumar, P. Muthukumaran, K. S. Kumar, and R. Karthikeyen, "Phytochemical characterization of bioactive compound from the ensete superbum seed powder," Indian Journal of Pure and Applied Biosciences, vol. 6, no. 6, pp. 635-643, 2019.

[28] N. K. Sethiya, K. Brahmbhat, B. Chauhan, and H. Mishra, "Antiurolithiatic activity of ensete superbum (Roxb) cheesman (wild banana ) pseudostem on ethylene glycol induced urolithiasis in rats," Indian Journal of Traditional Knowledge, vol. 16, no. 2, pp. 303-309, 2017.

[29] M. P. Neeta, N. Mukta, and K. Bilwa, "Comparative qualitative phytochemical analysis of sesamum indicum L," International Journal of Current Microbiology and Applied Sciences, vol. 2, no. 2, pp. 172-181, 2015.

[30] X. Chen, J. Xu, C. Zhang et al., "The protective effects of ursodeoxycholic acid on isoniazid plus rifampicin induced liver injury in mice," European Journal of Pharmacology, vol. 659, no. 1, pp. 53-60, 2011.

[31] M. M. G. Saravana, T. Ramakrishnan, V. Mani, and A. Achary, "Protective effect of crude sulphated polysaccharide from turbinaria ornata on isoniazid rifampicin induced hepatotoxicity and oxidative stress in the liver, kidney and brain of adult swiss albino rats," Indian Journal of Biochemistry and Biophysics, vol. 55, no. 8, pp. 237-244, 2018.

[32] W. Siddique, N. Rashid, N. Y. Warraich et al., "Comparison of hepatoprotective effect of silymarin and zinc sulfate against hepatotoxicity induced by isoniazid and rifampicin in albino rats," P J M H S, vol. 14, no. 1, pp. 113-119, 2020.

[33] P. S. Evan, P. Jerine, S. Prathap, and A. Geetha, "A comparison of hepatoprotective activity of Bacoside to Silymarin treatment against a combined Isoniazid and Rifampin-induced hepatotoxicity in female Wistar rats," Journal of Histotechnology, vol. 00, no. 00, pp. 1-9, 2019.

[34] M. Naji, Y. Al-khatib, and N. S. Al-haj, "Myrene D. Hepatoprotective activity of melittin on isoniazid and rifampicin Induced Liver damage in male albino rats," bioRxiv, vol. 40, no. 8, pp. 1-31, 2020.

[35] A. S. Chandra and P. Shanmugapandivan, "Hepatoprotective of eclipta alba methanolic extract in isoniazid and rifampicin proved oxidative hepatic injury," International Journal of Pharmacy Research and Technology, vol. 10, no. 2, pp. 74-79, 2020.

[36] P. Dikshit, M. Kumar Tyagi, K. Shukla, S. Sharma, J. Kaur Gambhir, and R. Shukla, "Hepatoprotective effect of stem of 
musa sapientum Linn in rats intoxicated with carbon tetrachloride," Annals of Hepatology, vol. 10, no. 3, pp. 333-339, 2011.

[37] M. T. Issa, A. N. Agbon, and S. U. Balogun, "Hepatoprotective effect of methanol fruit pulp extract of musa paradisiaca on carbon tetrachloride - induced liver toxicity in Wistar rats," Journal of Experimental and Clinical Anatomy, vol. 17, no. 1, pp. 1-7, 2019.

[38] J. Lin, J. Zhao, T. Li, J. Zhou, J. Hu, and Z. Hong, "Hepatoprotection in a rat model of acute liver damage through inhibition of CY2E1 activity by total alkaloids extracted from Rubus alceifolius poir," International Journal of Toxicology, vol. 30, no. 2, pp. 237-243, 2011.

[39] M. Giuseppantonio, B. Giovanna, C. Pierluigi, E. Semih, C. R. Andrea, and Z. Paolo, "Tannin profile, antioxidant properties, and antimicrobial activity of extracts from two Mediterranean species of parasitic plant Cytinus," BMC Complementary and Alternative Medicine, vol. 19, no. 82, pp. 1-11, 2019.

[40] C. King-thom, T. Y. Wong, C. Wei et al., "Tannins and human health: a review," Critical Reviews in Food Science and $\mathrm{Nu}$ trition, vol. 38, no. 6, pp. 421-464, 2016.

[41] M. Hossain, I. Manik, A. Matin, R. Chowdhury, and H. Rashid, "A study on the pharmacological effects and mechanism of action of alkaloids, glycosides and saponins," Pharmaceutical Chemistry Journal, vol. 6, no. 2, pp. 112-122, 2019.

[42] O. O. Elekofehinti, I. G. Adanlawo, J. A. Saliu, and S. A. Sodehinde, "Saponins from Solanum anguivi fruits exhibit hypolipidemic potential in rattusnovergicus," Der Pharmacia Lettre, vol. 4, no. 3, pp. 811-814, 2012.

[43] H. Kaur Sandhar, B. Kumar, S. Prasher, P. Tiwari, M. Salhan, and P. Sharma, "A review of phytochemistry and pharmacology of flavonoids," Internationale Pharmaceutica Sciencia, vol. 1, no. 1, pp. 25-41, 2011.

[44] S. A. Parameswari, C. M. Chetty, and K. B. Chandrasekhar, "Hepatoprotective activity of Ficus religiosa leaves against isoniazid + rifampicin and paracetamol induced hepatotoxicity," Pharmacognosy Research, vol. 5, no. 4, pp. 3-9, 2013.

[45] N. Ilyas, W. H. Awan, Z. L. Awan, and Z. Akram, "Comparison of Cassia fistula leaves and garlic in preventing drug induced liver injury in rats," Rawal Medical Journal, vol. 45, no. 3, pp. 725-727, 2020.

[46] G. A. Tilaye, M. F. Zerihun, K. A. Chuffa, M. Arayaselassie, and D. Seifu, "Vernonia amygdalina del (bitter leaf) extract ameliorates isoniazid (INH) induced liver injury in Swiss albino mice," bioRxiv, vol. 1, pp. 1-17, 2018.

[47] J. Huang, C. Zhang, D. Zhang, L. Li, X. Chen, and D. Xu, "Rifampicin-induced hepatic lipid accumulation : association with up- regulation of peroxisome proliferator- activated receptor $\gamma$ in mouse liver," PLoS One, vol. 11, no. 11, pp. 1-14, 2016.

[48] A. F. Wali, J. R. Pillai, Y. Al Dhaheri et al., "Crocus sativus L. extract containing polyphenols modulates oxidative stress and inflammatory response against anti-tuberculosis drugsinduced liver injury," Plants, vol. 9, no. 167, pp. 1-14, 2020.

[49] B. Bais and P. Saiju, "A meliorative effect of leucas cephalotes extract on isoniazid and rifampicin induced hepatotoxicity," Asian Pac J Trop Biomed, vol. 4, no. 2, pp. 633-638, 2014.

[50] V. G. Maruthappan and K. S. Shree, "Blood cholesterol lowering effect of adenanthera pavonina seed extract on antherogenic diet induced hyperlipidemia rats," International Journal of Pharmaceutical Sciences and Research, vol. 1, no. 7, pp. 87-94, 2010. 